\title{
ANÁLISE DOS ESTUDOS DE LOGÍSTICA REVERSA E ECONOMIA CIRCULAR APLICADOS NO GERENCIAMENTO DE RCC
}

\author{
Paulo Júnio Rodrigues Teixeira (UFSCAR) paulo.junio.rodrigues@ hotmail.com \\ José da Costa Marques Neto (UFSCAR) joseneto@ufscar.br
}

\section{Resumo}

Os estudos atuais motivados pela inovação do gerenciamento de resíduos da construção civil estão, em sua maioria, voltados para o desenvolvimento de técnicas e ferramentas aplicadas ao descarte ou disposição. Daqueles que não se aplicam a esse contexto, há diversos trabalhos que apresentam inovações técnico-científicas na gestão da produção em canteiros, que estudaram a aplicação de conceitos de logística reversa e de economia circular, visando a redução da emissão de resíduos ou o reaproveitamento destes. Entretanto, em muitos casos, tais melhorias estão voltadas para etapas de demolições e recuperações dos materiais ao final de sua vida útil, não tendo foco principal nos "materiais restos de obra". Sendo assim, visto a qualidade e os sucessos obtidos nos estudos que tratam da empregabilidade de técnicas na redução ou no reaproveitamento de resíduos da construção civil, gerados ainda na fase de execução de obras, esta análise visa averiguar o direcionamento que vem sendo tomado nas pesquisas voltadas para a inovação do gerenciamento dos resíduos da construção civil (RCC). Ademais, este estudo visa também elucidar o número de trabalhos sobre o tema supracitado, desenvolvidos e publicados nos últimos 5 anos, disponíveis no portal de pesquisa de periódicos ScienceDirect®. Este trabalho é fase de uma pesquisa a nível de mestrado, que pretende desenvolver uma ferramenta de gerenciamento de RCC, utilizando técnicas de logística reversa, de economia circular e da bolsa de resíduos, realizada na oportunidade de otimizar a ferramenta com a elaboração de um banco de dados contendo alternativas de redução, descarte ou disposição, disponíveis e validadas em pesquisas científicas. Além da função de acervo de soluções para os resíduos, a ferramenta visa estimar e quantificar tipos e quantidades de entulhos em uma determinada obra, em função dos métodos construtivos aplicados e do histórico de execuções de uma determinada construtora.

Palavras-Chaves: construção civil, gestão de resíduos, resíduos da construção civil.

\section{Introdução}


Existem diversas técnicas de reemprego e reutilização de resíduos da construção, que contemplam os conceitos de economia circular, porém pouco estudo é voltado para as atividades de planejamento e de gerenciamento de obras que viabilizem a utilização destas. A implementação da economia circular na construção civil é uma das principais vias para se combater o elevado consumo de matéria prima e reduzir a alta contribuição do setor, na geração de resíduos sólidos urbanos. Este conceito, parte do princípio de devolver ao resíduo o seu valor como material, e assim transportá-lo para o início da cadeia produtiva ainda como entulho. Atuando além de atividades de reciclagem e de logística reversa, este, por sua vez, impacta também na redução do consumo energético dos demais setores, principalmente nos de produção de matéria prima e naqueles que atuam na reciclagem de componentes da construção.

Estudos recentes voltados para a aplicação da economia circular na construção, concentram maiores esforços na indústria da demolição, criando bancos de materiais e atuando no conceito de passaporte de materiais, além da aplicação de alternativas de desconstrução que viabilizem estas atividades. Porém, conforme se observa em pesquisas recentes, o volume de resíduos obtidos em obras de novas edificações, tem representatividade equivalente àquele de demolições. Tendo em vista tal observação, esforços de mesma amplitude devem estar voltados para a solução da problemática dos resíduos tanto em demolições como em novas construções, o que não ocorre no atual cenário das pesquisas sobre o tema.

Neste contexto, este artigo pretende, portanto, analisar os trabalhos disponíveis no portal de pesquisa de periódicos ScienceDirect ${ }^{\circledR}$, publicados nos últimos 5 anos, que tratam do gerenciamento de resíduos na construção civil. A partir destes, visa também analisar o foco que vem sendo tomado nesta linha pesquisa e averiguar o número de estudos voltados para a implementação de técnicas de logística reversa e de economia circular, no tratamento dos resíduos gerados em obras de novos empreendimentos.

Essa análise servirá de base para um posterior estudo das inovações técnico-científicas propostas nos artigos avaliados, em que será desenvolvida uma ferramenta computacional de gerenciamento de resíduos sólidos, não tendo foco de aplicação em demolições.

\section{Gerenciamento de resíduos da construção civil}


O setor da construção civil é conhecido como a principal fonte de geração de resíduos sólidos. Segundo a Associação Brasileira de Empresas de Limpeza Pública e Resíduos Especiais (ABRELPE, 2012), 55\% do resíduo sólido urbano coletado nos municípios brasileiros em 2012, foram provenientes de construções e reformas. Já Arif et al. (2012) estima-se que $40 \%$ dos resíduos sólidos urbanos gerados, advém de atividades da construção civil.

A geração de grandes quantidades de resíduos de diversas naturezas, se dá devido aos métodos construtivos de caráter artesanal que ainda são utilizados no setor, principalmente no sistema construtivo convencional nacionalmente empregado (BRASILEIRO; MATOS, 2015). Miotto (2013 apud Silva et al., 2015, p. 41) salienta que a geração excessiva de resíduos na construção civil está relacionada a baixa qualidade da mão de obra, ao emprego de técnicas construtivas que não fazem uso da racionalização, à falhas nos transportes, ao excesso de produção, entre outros.

A Lei $\mathrm{n}^{\circ}$ 12.305, de 2 de Agosto de 2010, estabelece que os resíduos sólidos deste setor, são aqueles gerados a partir de construções, reformas, reparos e demolições, incluindo os provenientes da preparação e escavação do terreno. Segundo Rodrigues et al. (2015), o tratamento destes subprodutos do setor estão condicionados na solução de algumas incógnitas, relacionadas aos tipos de resíduos gerados, à destinação destes, à minimização dos impactos produzidos e às formas de reaproveitamento destes materiais. Desta forma, entende-se que o gerenciamento da emissão e do tratamento destes, está sujeito a adaptação cultural de empresas do setor e de seus envolvidos, às metodologias que prezem pela otimização do uso de materiais e do manejo correto dos entulhos.

Já nas cidades, aspectos sociais, econômicos e ambientais, sofrem interferência devido à falta de gerenciamento dos entulhos das construções (BRASILEIRO; MATOS, 2015), sendo assim, observa-se que os efeitos da ausência deste processo não implicam apenas na própria obra, mas também nos resultados da gestão global.

O consumo exorbitante de recursos naturais na construção civil é outro ponto que implica na temática de geração de resíduos sólidos, pois o setor abrange desde a extração de insumos até a construção propriamente dita (SILVA et al., 2015). Devido ao amplo volume de material empregado, estimar com precisão os resíduos gerados em projetos de construção é um fator crítico da implementação bem-sucedida do gerenciamento de resíduos. Contudo, modelos quantitativos podem ser empregados nessa atividade, conforme é proposto por Li et al. (2016). 
Cabe ressaltar ainda que a simples triagem e classificação dos resíduos, como etapa predecessora para a destinação em aterros, não constitui uma completa ferramenta para o gerenciamento dos restos de obras. Acredita-se que o estudo das propriedades dos entulhos gerados e a identificação de estratégias de redução dos seus índices, e consequentemente da sua emissão, constituem dados para a formulação de uma ferramenta que seja capaz de gerenciá-los ainda na etapa de planejamento de obra.

\subsection{Logística reversa}

Observa-se que a reciclagem e a logística reversa vão além do que o descarte adequado do entulho pode oferecer, uma vez que colaborara para a gestão sustentável da organização, possibilitando o reuso dos RCC e diminuindo impactos ambientais, conforme é concluído por Ladeira et. al. (2014). Deste modo, entende-se a logística reversa como uma segunda alternativa para os materiais que já não apresentam vias de emprego na obra, mas que ainda apresentam valor como recurso.

Em um estudo realizado a partir de uma amostra representativa no município de São Paulo, Paschoalin Filho et al. (2017) constatou que apenas 22\% das construtoras declaram ter algum tipo de iniciativa em relação à adoção de procedimentos de logística reversa ou de absorção dos RCC, utilizando o reuso ou a reciclagem em canteiros de obras. Já Nunes et al. (2009) salienta que no Brasil, os gestores municipais podem aumentar a reutilização de resíduos de construção e demolição, implementando uma rede reversa desses materiais, tentando otimizar fluxos e atividades, bem como introduzir incentivos para que as vias de distribuição reversível se tornem viáveis.

Hosseini et al. (2015) relatam que a maioria dos construtores tratam a direção do fluxo de materiais na cadeia de suprimentos da construção de forma linear, quer dizer, tratando como materiais a partir da extração da matéria prima, passando pelo seu consumo e por fim, no descarte. Tal visão não permite integrar o processo de reciclagem e a logística reversa, aos sistemas construtivos.

Por fim, Marcomendes e Cardoso (2005) ressaltam que "o desenvolvimento da logística reversa tem maiores possibilidades de sucesso quando a função das empresas fornecedoras, as quais atuam com a indústria e, portanto, estão expostos a menos variáveis e imprevistos do que a empresa construtora". Os autores concluem ainda que empresas fornecedoras e executoras são interdependentes na instauração do processo progressivo da 
logística reversa. Observa-se que a eficácia desta no âmbito da economia circular, apresentando maior aplicação na indústria fornecedora de materiais de construção.

\subsection{Economia circular}

Segundo Stahel (2016), "uma economia circular transforma bens que estão no final de sua vida útil em recursos para outros". Nesse sentido, entende-se como a economia de energia e a economia de recursos, através da otimização do uso de materiais e componentes da construção. Optando por metodologias de trabalho que prezem pela reintegração dos resíduos na cadeia produtiva, tem-se economia significativa na aquisição de novos materiais e no gasto energético com tratamentos por reciclagem e disposições em aterros, além, é claro, da redução da emissão de resíduos e do impacto ambiental gerado por eles. O assunto é fortemente tratado em obras de demolições, porém encontra-se em etapa inicial de estudo no que se refere a torná-lo uma alternativa de planejamento em novas obras.

Kibert (2008 apud Akanbi et al., 2018, p. 175), ressalta que mundialmente 50\% de todo o lixo gerado na construção civil é proveniente de atividades de fim de vida, ou seja, de demolição, logo, verifica-se que boa parcela de resíduos do setor é proveniente de obras de novas edificações. Tal observação permite viabilizar maiores oportunidades para a aplicação dos conceitos de economia circular em resíduos de materiais que ainda estão no início do seu ciclo de vida, ao se comparar com os entulhos de demolições, que já cumpriram com seu período de utilização e necessitam de maiores esforços para que o conceito seja aplicado.

Bocken et al. (2016) concluiu que a utilização da economia circular com loops traduz o sentindo de estender o período de utilização dos produtos, enquanto economia circular com loops fechados, visa o encerramento do ciclo entre o pós-uso e a produção, ou seja, reciclagem. Acredita-se que a reutilização de materiais considerados entulhos, aproveitando suas propriedades e características em seu estado de "resíduo", constitui melhor significado para a economia circular do que a simples reciclagem.

$\mathrm{Na}$ construção civil, maiores esforços estão destinados ao estudo da aplicação do conceito na recuperação de materiais ao final da vida útil da edificação, ou seja, na desconstrução de edifícios para posterior reaproveitamento dos componentes, conforme é proposto por Akanbi et al. (2018). Através do seu estudo, o autor, utilizando a ferramenta BIM, propôs um modelo para avaliar o desempenho de componentes estruturais de edifícios, desde a fase de projeto, para serem "salvos", ou seja, recuperados para a reutilização ao final 
da vida útil do edifício. O estudo concluiu que edifícios com estruturas de aço, conexões desmontáveis e conjuntos pré-fabricados, apresentam materiais recuperáveis que na maioria das vezes são reutilizáveis.

Já Leising et al. (2018) desenvolveu um estudo observando a aplicação do conceito de economia circular em três fases de um edifício na construção civil: um prédio novo, uma reforma e um projeto de demolição. Como conclusão para o estudo, foi possível observar que no setor, a economia circular requer novos tipos de colaboração na cadeia de suprimentos.

Por fim, a partir de uma revisão geral sobre o assunto, Adams et al. (2017) relata que a aplicação do conceito na construção civil ainda está na sua "infância", sendo limitadamente tratado como a minimização e reciclagem de resíduos. Com sua pesquisa, concluíram que a indústria, os clientes, projetistas e subcontratados são os menos informados sobre o assunto, sendo esse um desafio chave para uma maior implementação, além da ausência de incentivos para a adoção do conceito.

\section{Metodologia}

Para atingir o resultado deste trabalho, foi feita inicialmente uma revisão bibliográfica com o objetivo de contextualizar as temáticas de logística reversa e economia circular, dentro da construção civil. Buscou-se também abordar, sem muita ênfase, o gerenciamento de resíduos sólidos no setor.

Em segundo momento, procedeu-se com a pesquisa utilizando a ferramenta de busca avançada disponível no portal de periódicos ScienceDirect@. Para a pesquisa, seguiu-se com os procedimentos listados a seguir, de modo a obter resultados que :

- Buscou-se por termos duplos, realizando 3 pesquisas: "waste management" e "construction", "reverse logistic" e "construction", e "circular economy" e "construction";

- Buscou-se os termos na campo Title, abstract or author-specified keywords em detrimento ao campo Find articles with these terms, por apresentar filtragem melhor otimizada;

- O campo Year(s) foi preenchido com “2016-2020”;

- Na opção Article types foi selecionada a Research Articles;

- As demais opções da busca avançada não foram preenchidas ou selecionadas. 
Após realizar a pesquisa, houve a leitura dinâmica do resumo e objetivos de cada artigo buscado e a partir disto, ocorreu a filtragem e a exclusão daqueles que não se enquadravam no contexto buscado, porém não foram filtrados pela ferramenta de busca. Para os que se enquadravam no tema, ocorreu a separação conforme seu foco de estudo.

Os artigos analisados foram separados conforme seu foco de aplicação, em construções ou em demolições. Foram analisados também se tratavam de estudos sobre logística reversa (reemprego dos resíduos após sofrerem transformações ou reciclagem), economia circular (reutilização dos resíduos, dentro ou fora do setor), gestão ou gerenciamento dos resíduos (atividades de planejamento e otimização do processo construtivo com foco na redução das emissões, estimativas de geração, descarte ou disposição, dentre outras atividades que foquem nas soluções a serem tomadas em relação aos resíduos) e estudo das propriedades dos resíduos (estudo das propriedades do material na oportunidade identificar possibilidades de recuperação, transformação e inserção em outros setores, e verificação dos impactos ambientais causados pelo descarte ou disposição do material). Os artigos que tratavam da reciclagem de resíduos foram distribuídos dentro das 4 alternativas listadas, por apresentarem melhores semelhanças com essas opções.

Optou-se pela utilização do portal de busca de periódicos ScienceDirect®, em detrimento a outras ferramentas de pesquisa ou até mesmo buscadores nas próprias bases, pelas limitações de conteúdos que estes demais portais apresentam, se comparados ao utilizado.

\section{Resultado}

Para as três pesquisas realizadas foram obtidos os resultados apresentados na Figura 1.

Figura 1 - Número de Artigos Retornados

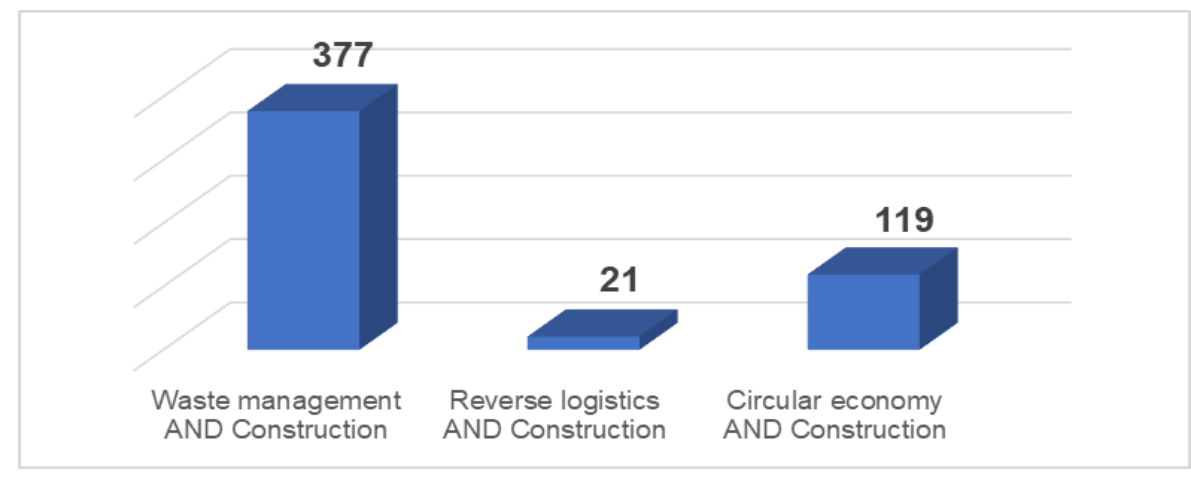

Fonte: Próprio Autor (2020) 
Dos 517 artigos buscados e avaliados, foi observado que uma grande parcela destes não se enquadravam no tema da pesquisa, conforme é apresentado na Figura 2. Estes artigos foram encontrados pelo buscador por apresentarem os dois termos buscados, apresentando alguma ligação com estes, mas com foco destoante daquele que se objetiva com este trabalho.

Observou-se também que as três pesquisas retornaram alguns resultados iguais. Deste modo, para uma melhor apreciação dos resultados deste trabalho, estes foram subtraídos do total de artigos dentro do contexto, conforme também é apresentado na Figura 2.

Figura 2 - Dentro do Tema x Fora do Tema x Duplicados

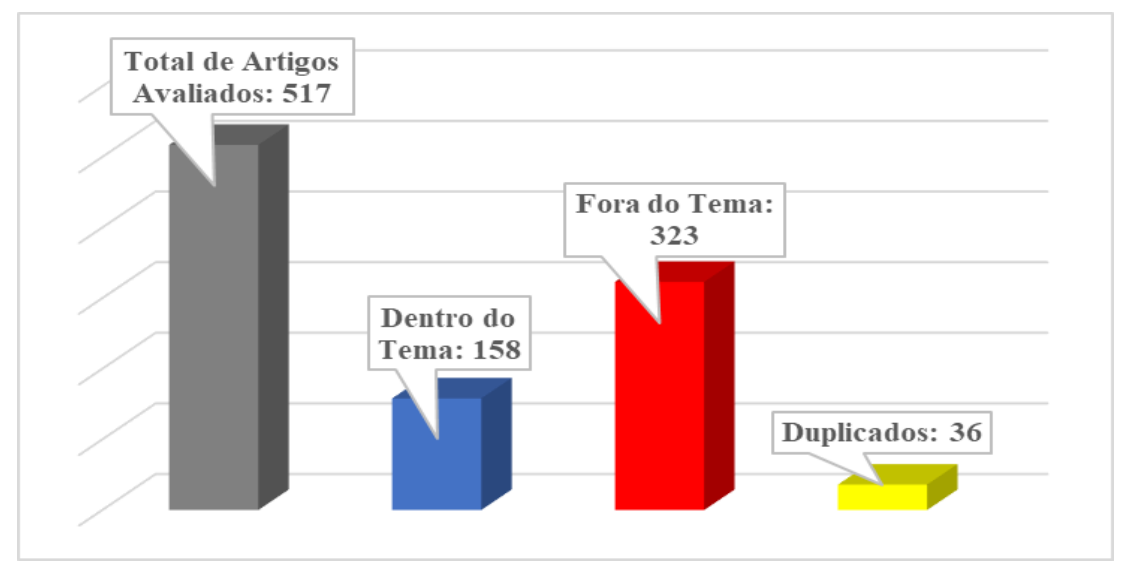

Fonte: Próprio Autor (2020)

A partir dos 158 artigos que estavam dentro do contexto, houve a classificação conforme proposto na metodologia. As Figura 3 e Figura 4, apresentam os resultados com base no foco de aplicação dos estudos e com base na temática observada pelo autor, respectivamente.

Figura 3 - Foco de Aplicação

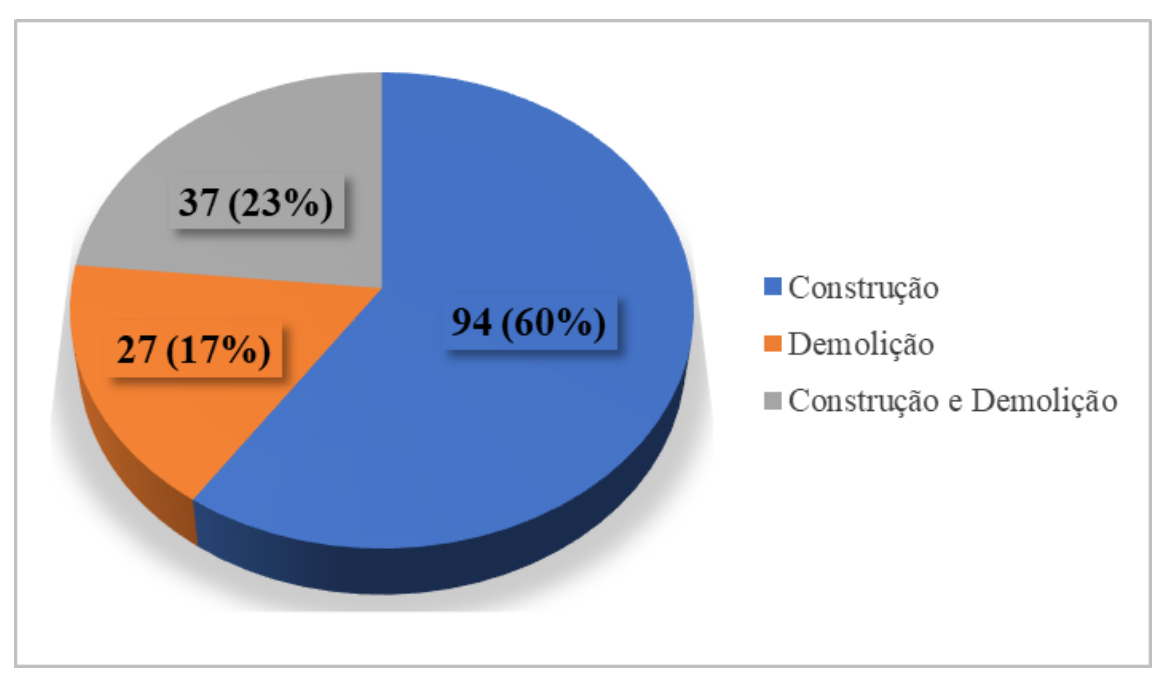

Fonte: Próprio Autor (2020) 


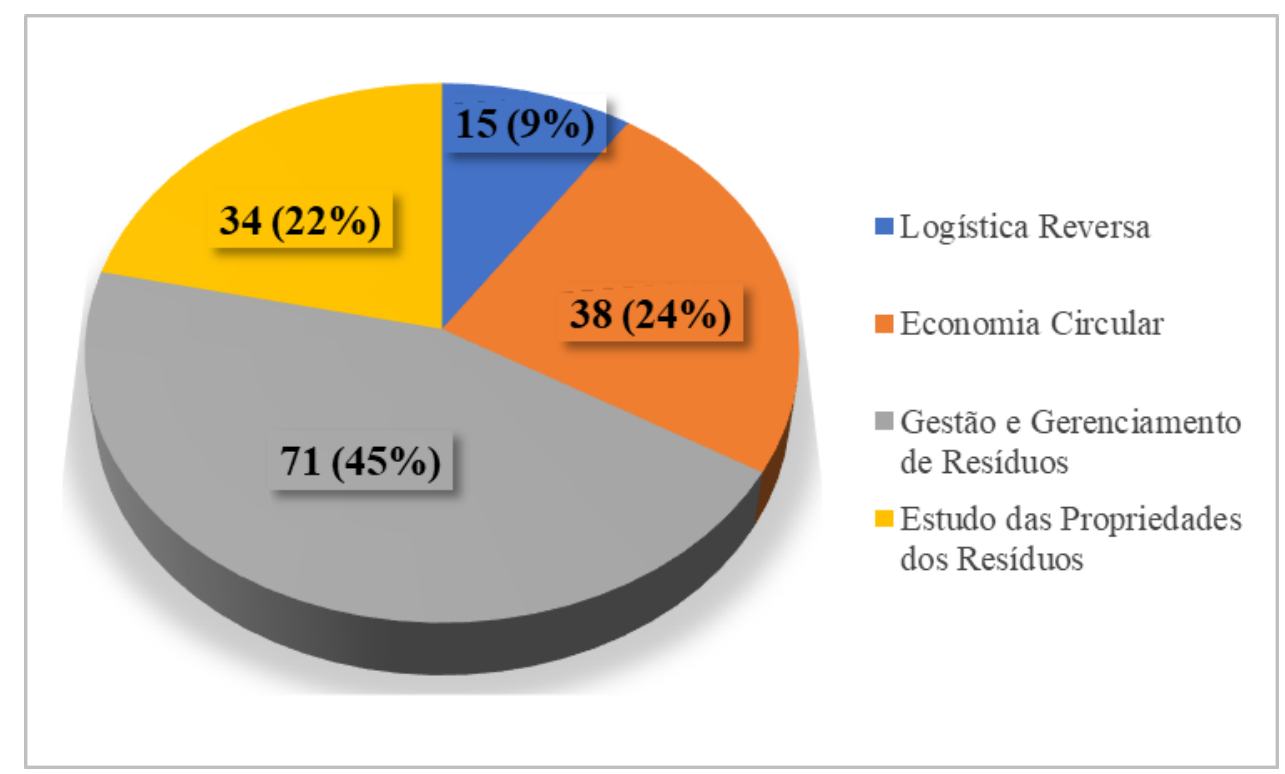

Fonte: Próprio Autor (2020)

\section{Análise dos resultados}

Em um primeiro momento, coube avaliar o elevado número de artigos que estavam fora do contexto buscado, mas que foram retornados pela ferramenta de busca. Esse resultado se deu pelo fato de que a temática proposta condizia apenas com os resíduos obtidos e gerados na construção civil. Observou-se que dos 323 artigos que destoavam do contexto buscado, uma grande parcela tratava da aplicação de resíduos de outros setores industriais, dentro de materiais de construção (aplicação de resíduos da indústria química, de setores de beneficiamento de matéria-prima e estudo das propriedades dos novos materiais desenvolvidos com estes, foram os principais trabalhos retornados neste montante). Cabe ressaltar também, que uma pequena parcela deste grupo apresentava foco ou temática totalmente distinta do tema deste trabalho, não tratando da construção civil e por vezes, se quer, tratando do estudo de resíduos. Sobre estes, ressalta-se ainda que este grupo abrangeu alguns artigos que tratavam sobre resíduos da construção, mas que não apresentavam qualquer ligação com pelo menos uma das 4 temáticas buscadas, mesmo que estes se apresentaram em um número muito pequeno.

Em relação ao foco de aplicação, observou-se que mesmo ao buscar pelos termos "circular economy" e "construction", a ferramenta não retornou muitos resultados sobre estudos com aplicação estrita em obras de demolições, e para os poucos que tinham este foco, uma grande maioria destes também apresentavam aplicação em construções. Mesmo que a 
temática "economia circular" trate de maneira mais ampla da recuperação do material ao final de seu ciclo de vida, observou que a maior parcela dos estudos que vislumbravam este tema, tratavam da aplicação do conceito em construções, e não em demolições. Já dos artigos que comtemplaram a logística reversa, a totalidade tinha foco em construções.

Sobre as temáticas identificadas, observou-se que o tema gestão e gerenciamento de resíduos na construção civil, tratando da disposição, destinação ou planejamento da obra com foco na redução destes, foi assunto principal em quase metade dos artigos avaliados. Mesmo sendo do senso comum que a ideia de "resíduo zero" na construção civil, ainda se encontre em um patamar de difícil alcance, este dado demostra que a preocupação em relação à recuperação e reutilização dos restos de obras, ainda se encontra em fases iniciais de estudo ou não se trata de uma importância principal, quando o assunto é resíduos do setor. Observase também que a logística reversa, por mais que seja mais antiga e que abranja o tema economia circular, apresentou menores resultados do que este. Não menos importante, observa-se que estudos sobre a identificação das propriedades dos resíduos, mesmo que ainda seja desenvolvida de modo a apenas descrevê-las, foi o segundo tema mais tratado em relação aos resíduos da construção. Acredita-se que tal cenário possa alavancar os estudos em relação a logística reversa e a economia circular, visto que as aplicações daqueles materiais que já tem suas propriedades bem definidas, apresentam maiores possibilidades de realização.

Da totalidade de artigos buscados, observou que o buscador retornou maiores e melhores resultados nos anos mais recentes, indicando assim uma crescente preocupação com a temática e com desenvolvimento de trabalhos, por parte do meio científico.

Ressalta-se assim que vários artigos apresentavam mais de uma temática, podendo estar contidos em mais de um grupo, porém definiu-se como àquela que apresentava maior relevância.

\section{Conclusão}

Optar por soluções que prezem pela economia circular ou pela logística reversa, quando o assunto são os resíduos da construção civil, é uma opção pouco difundida no meio científico, que ainda carece de muita pesquisa. No que diz respeito a economia circular, esta enfrenta dificuldades para que o enfoque se volte para a construção, visto que este setor tem características nômades, pouca padronização de seus processos e produtos únicos. 
A partir do que fora alcançado com esta pesquisa, acredita-se que maiores esforços devam ser direcionados aos estudos que tratam da valorização dos resíduos e das possibilidades de recuperação e reutilização. Enquanto a meta de "resíduo zero" para este setor de produção tem característica quase inalcançável e as emissões de resíduos estão em patamares elevados, é importante salientar que a sustentabilidade na construção se dará apenas com a valorização dos recursos empregados, prezando assim pelo reaproveitamento e a recuperação daquilo que hoje ainda é considerado como lixo.

\section{REFERÊNCIAS}

ADAMS, K. T.; OSMANI, M.; THORPE, T.; THOMBACK, J. Circular economy in construction: current awareness, challenges and enablers. Proceedings of the Institution of Civil Engineers - Waste and Resource Management, v. 170, n. 1, p. 15-24, feb. 2017.

ABRELPE - ASSOCIAÇÃO BRASILEIRA DE EMPRESAS DE LIMPEZA PÚBLICA E RESÍDUOS ESPECIAIS. Panorama dos Resíduos da Construção no Brasil. 2012. Acessado em: 23/07/2019. Disponível em: 〈http://a3p.jbrj.gov.br/pdf/ABRELPE\%20\%20Panorama2012.pdf>

AKANBI, L. A.; OYEDELE, L. O.; AKINADE O. O.; AJAYI, A. O.; DELGADO, M. D.; BILAL, M.; BELLO, S. A. Salvaging building materials in a circular economy: A BIM-based whole-life performance estimator. Resources, Conservation and Recycling, v. 129, n. November 2017, p. 175-186, apr. 2018.

ARIF, M.; BENDI, D.; TOMA-SABBAGH, T.; SUTRISNA, M. Construction waste management in India: An exploratory study. Construction Innovation, v. 12, n. 2, p. 133-155, 2012.

BOCKEN, N. M. P.; PAUW, I. de; BAKKER, C.; VAN DER GRINTEN, B. Product design and business model strategies for a circular economy. Journal of Industrial and Production Engineering, p. 308-320, apr. 2016.

HOSSEINI, M. R.; RAMEEZDEEN, R.; CHILESHE, N.; LEHMANN, S. Reverse logistics in the construction industry. Waste Management and Research, v. 33, n. 6, p. 499-514, 2015.

BRASILEIRO, L. L.; MATOS, J. M. E. Revisão bibliográfica: reutilização de resíduos da construção e demolição na indústria da construção civil. Cerâmica, v. 61, n. 358, p. 178-189, 2015.

LADEIRA, R.; VERA, L. A. R.; TRIGUEIROS, R. E. Gestão dos resíduos sólidos e logística reversa: um estudo de caso em uma organização do setor de construção. Gestão \& Planejamento, v. 15, n. 2, p. 283-304, mai./ago. 2014.

LEISING, E.; QUIST, J.; BOCKEN, N. Circular Economy in the building sector: Three cases and a collaboration tool. Journal of Cleaner Production, v.176, p. 976-989, mar. 2018.

LI, Y., ZHANG, X.; DING, G.; FENG, Z. Developing a quantitative construction waste estimation model for building construction projects. Resources, Conservation and Recycling, v. 106, p. 9-20, 2016.

MARCONDES, F. C.; CARDOSO, F. F. Contribuição para aplicação do conceito de logística reversa na cadeira de suprimentos da construção civil. In: IV Simpósio Brasileiro de Gestão e Economia da Construção / I Encontro Latino-americano de Gestão e Economia da Construção: Construção na América Latina: inclusão e modernização (IV SIBRAGEC / I ELAGEC). Porto Alegre: UFRGS, 2005.

NUNES, K. R. A.; MAHLER, C. F.; VALLE, R. A. Reverse logistics in the Brazilian construction industry. Journal of Environmental Management, v. 90, n. 12, p. 3717-3720, may. 2009.

PASCHOALIN FILHO, J. A.; BEZERRA, P. R. L.; OLIVEIRA, L. R. G. J. de; FARIA, A. C. de. 
Gerenciamento de resíduos de construção civil em edifícios residenciais no município de são paulo. Revista de Gestao Social e Ambiental, v. 11, n. 1, p. 73-89, jan./abr. 2017.

RODRIGUES, G. da C.; OLIVEIRA, T. A. A. de; NERY; I. C.; JUCÁ, H. L. de A. Utilização de ferramentas da qualidade em um plano de gerenciamento de resíduos da construção civil. In: IV SIMPÓSIO

INTERNACIONAL DE GESTÃO DE PROJETOS, INOVAÇÃO E SUSTENTABILIDADE, 2015, São Paulo/SP. Anais do IV SINGEP. São Paulo: SINGEP, 2015.

SILVA, O. H. da; UMADA, M. K.; POLASTRI, P.; ANGELIS NETO, G. de; ANGELIS; B. L. D. de; MIOTTO; J. L. Etapas Do Gerenciamento De Resíduos Da Construção Civil. Revista Eletrônica em Gestão, Educação e Tecnologia Ambiental, v. 19, n. 1, p. 39-48, 2015.

STAHEL, W. R. The circular economy. Nature, v. 532, p. 435-438, mar. 2016. 